\section{SAT0336 MEASUREMENT PROPERTIES OF THE MINIMAL DISEASE ACTIVITY CRITERIA FOR PSORIATIC ARTHRITIS}

L.C. Coates ${ }^{1}$, V. Strand ${ }^{2}$, H. Wilson ${ }^{3}$, B.S. Stolshek ${ }^{4}$, A. Samad ${ }^{4}$, J. Chung ${ }^{4}$, D. D. Gladman ${ }^{5}$, P. Mease ${ }^{6} .{ }^{1}$ NDORMS, University of Oxford, Oxford, UK; ${ }^{2}$ Division of Immunology/Rheumatology, Stanford University, Stanford, $C A ;{ }^{3}$ Evidera, Seattle, WA; ${ }^{4}$ Amgen Inc., Thousand Oaks, CA, USA $;{ }^{5}$ University of Toronto, Toronto Western Hospital, Toronto, Canada; ${ }^{6}$ Swedish Medical Center and University of Washington, Seattle, WA, USA

Background: Psoriatic arthritis (PsA) is a heterogeneous inflammatory joint disease, which generally occurs in combination with psoriasis. Key defining features include joint inflammation, psoriasis, nail changes, axial disease, dactylitis, and enthesitis. A composite endpoint that captures all aspects of the disease is critical to understanding disease activity. Recognising the need for a measure of acceptable disease status that equates to a clinically meaningful outcome for patients, the Group for Research and Assessment of Psoriasis and PsA followed methodology from Outcome Measures in Rheumatology to develop the Minimal Disease Activity (MDA) criteria. ${ }^{1}$ Since initial publication of the MDA criteria, which consist of physician and patient-reported measures, they have been used in a number of randomised controlled trials (RCTs) and long-term observational studies (LOS). These studies provide an opportunity to systematically evaluate the measurement properties of the MDA.

Objectives: To examine evidence of the validity and the ability of the MDA to detect change in published PsA studies.

Methods: A targeted literature review was conducted in MEDLINE and EMBASE to identify publications that provided evidence of the validity or ability of the MDA criteria to detect change. LOS that reported data without a comparator and studies that examined the relationship between achievement of MDA and baseline variables were excluded. Abstracts of conference proceedings were included if they reported on phase 3 results not yet formally published. Relevant data were extracted and summarised in tabular format, and reviewed by an independent investigator.

Results: 20 publications were identified that met inclusion criteria. In both LOS and RCTs, patients in MDA consistently had decreased inflammatory markers (ie CRP), decreased radiographic joint erosions and progression of structural damage over time, and reported less disease impact on patient-reported outcomes. The consistency of these findings in both LOS and RCTs provide support for the validity of the MDA. Nine RCTs demonstrated superior efficacy to the respective comparator arm. All nine of these RCTs also reported a significantly greater percentage of patients in the active treatment arms met MDA criteria vs. Placebo. These results provide support for the ability of the MDA to detect between-subjects change. Two LOS were also identified that reported on the association with achievement in MDA following initiation of treatment with bDMARDs. demonstrated a significant likelihood of patients beginning treatment with bDMARDs to meet MDA after 4, 6, and 12 months of treatment, providing support for the MDA to detect change in a real-world setting.

Conclusions: Published evidence indicates that the MDA is a validated measure with the ability to detect change in PsA patients. The MDA criteria offer a practical, holistic, and clinically meaningful endpoint for patients and clinicians to assess the impact of specific treatment interventions on PsA disease activity.

\section{REFERENCE:}

[1] Coates LC, Helliwell PS. Arthritis Care Res (Hoboken) 2010;62(7):965969.

Disclosure of Interest: L. Coates Grant/research support from: AbbVie, Pfizer, Novartis, Celgene, Consultant for: AbbVie, Amgen, BMS, Celgene, Galapagos, Janssen, Eli Lilly and Co., MSD, Novartis, Pfizer, Prothena, Sun Pharma, UCB, V. Strand Consultant for: AbbVie, Amgen, Bayer, Boehringer Ingelheim, Celltrion, Crescendo, Genentech/Roche, GSK, Janssen, Lilly, Merck, Novartis, Pfizer, Samsung, Sandoz, UCB, H. Wilson Consultant for: Amgen Inc., B. Stolshek Shareholder of: Amgen Inc., Employee of: Amgen Inc., A. Samad Shareholder of: Amgen Inc., Employee of: Amgen Inc., J. Chung Shareholder of: Amgen Inc., Employee of: Amgen Inc., D. Gladman Grant/research support from: Amgen, AbbVie, Celgene, Eli Lilly, Janssen, Novartis, Pfizer, UCB, Consultant for: AbbVie, Amgen, BMS, Celgene, Eli Lilly, Janssen, Novartis, Pfizer, UCB, P. Mease Grant/ research support from: AbbVie, Amgen, Bristol Myers Squibb, Celgene, Janssen, Lilly, Novartis, Pfizer, Sun, UCB, Consultant for: AbbVie, Amgen, Bristol Myers Squibb, Celgene, Janssen, Lilly, Novartis, Pfizer, Sun, UCB, Speakers bureau: AbbVie, Amgen, Bristol Myers Squibb, Celgene, Genentech, Janssen, Novartis, Pfizer, UCB

DOI: 10.1136/annrheumdis-2018-eular.3821

\section{SAT0337 \\ BIOLOGIC DMARDS AND PSORIATIC ARTHRITIS IN EUROPE IN 2016/2017: CHARACTERISTICS OF PATIENTS STARTING TNF-INHIBITORS OR USTEKINUMAB IN THE ONGOING PSABIO OBSERVATIONAL COHORT STUDY}

L. Gossec ${ }^{1}$, P. Athanassiou ${ }^{2}$, P. Bergmans ${ }^{3}$, K. de Vlam ${ }^{4}$, E. Gremese ${ }^{5}$, B. JovenIbáñez $^{6}$, T.V. Korotaeva ${ }^{7}$, F. Liotée ${ }^{8}$, M.T. Nurmohamed ${ }^{9}$, P.P. Sfikakis ${ }^{10}$, S. Siebert ${ }^{11}$, P. Smirnov ${ }^{12}$, E. Theander ${ }^{13}$, J.S. Smolen ${ }^{14} .{ }^{1}$ Sorbonne Université, Paris, France; ${ }^{2}$ St. Paul (Agios Pavlos) Hospital, Thessaloniki, Greece; ${ }^{3}$ JanssenCilag B.V., Breda, Netherlands: ${ }^{4}$ University Hospitals Leuven, Leuven, Belgium; ${ }^{5}$ Fondazione Policlinico Gemelli-Catholic University of the Sacred Heart, Rome, Italy; ${ }^{6}$ University Hospital 12 de Octubre, Madrid, Spain; ${ }^{7}$ V.A. Nasonova Research Institute of Rheumatology, Moscow, Russian Federation; ${ }^{8} \mathrm{Hoppital}$ Lariboisière and Unversity of Paris Diderot, Paris, France; ${ }^{9}$ Amsterdam Rheumatology and Immunology Center, VU University Medical Centre and Reade, Amsterdam, Netherlands; ${ }^{10}$ University of Athens Medical School, Athens, Greece; ${ }^{11}$ University of Glasgow, UK; ${ }^{12}$ Janssen Pharmaceutica NV, Moscow, Russian Federation; ${ }^{13} \mathrm{Janssen}$ EMEA, Issy-les-Moulineaux, France; ${ }^{14}$ Medical University of Vienna, Vienna, Austria

Background: The PsABio study (ClinicalTrials.gov Id: NCT02627768) was developed to evaluate the efficacy, tolerability and persistence of TNF inhibitors (TNFi) and ustekinumab (UST) for patients with psoriatic arthritis (PsA) starting $1 \mathrm{st}$, 2nd or 3rd line biologic disease-modifying antirheumatic drugs (bDMARDs) in real-world routine care.

Objectives: In this interim analysis, the objective was to describe the profile of patients starting either UST or TNFi in routine clinical care in 8 European countries.

Methods: Between Dec 2015 and, Aug 2017 patients were enrolled in Italy, Greece, Russia, France, United Kingdom, The Netherlands, Spain and Belgium and had valid baseline data available. Descriptive baseline characteristics for the UST and TNFi cohorts were compared.

Results: 563 consecutive patients were analysed (278 UST- and $285 \mathrm{TNFi}$ treated patients): mean (SD) age 49.3 (12.4) years, disease duration 7.2 (7.5) years; $49.6 \%$ were men and most had polyarticular disease (Table). Among comorbidities, cardiovascular disease $(38.9 \%)$ and obesity $(30.4 \%)$ were most frequent; $11.5 \%$ had anxiety or depression. $25.6 \%$ of patients were current smokers. TNFis were more often given as 1 st line bDMARD than UST (56.8\% vs $39.2 \%$ ). For patients receiving their $1 \mathrm{st} \mathrm{bDMARD,} \mathrm{the} \mathrm{prevalence} \mathrm{of} \mathrm{concomitant} \mathrm{conven-}$ tional synthetic (cs) DMARDs at baseline was: UST: $46.8 \%$ (39.5\% methotrexate [MTX]) and TNFi: 53.7\% (39.5\% MTX). Among 166 patients who received a 2nd or 3rd bDMARD and had no ongoing csDMARDs at baseline, $66.3 \%$ received UST and $33.7 \%$ received TNFi. The most prescribed TNFi were etanercept (34.0\%), adalimumab (25.3\%) and golimumab (19.6\%); $12.6 \%$ were TNFi biosimilars. The majority of patients on UST received the recommended dose, although $27.8 \%(10 / 36)$ of patients $>100 \mathrm{~kg}$ started with $45 \mathrm{mg}$ every 3 months. Disease activity was moderate to high with more axial, skin and nail involvement in the UST group.

Abstract SAT0337 - Table 1. Baseline characteristics for all patients and by bDMARD in PsABio as of August 2017. Values are mean (SD), if not otherwise indicated.

\begin{tabular}{|l|c|c|c|}
\hline & $\begin{array}{c}\text { UST } \\
(n=278)\end{array}$ & $\begin{array}{c}\text { TNFI } \\
(n=285)\end{array}$ & $\begin{array}{c}\text { All } \\
(n=563)\end{array}$ \\
\hline Age, yrs & $49.9(12.2)$ & $48.8(12.6)$ & $49.3(12.4)$ \\
\hline Disease duration since diagnosis, yrs & $7.7(7.6)$ & $6.7(7.4)$ & $7.2(7.5)$ \\
\hline Sex (male), \% & 47.8 & 51.2 & 49.6 \\
\hline Comorbidities (all), \% & 62.9 & 55.4 & 59.1 \\
\hline Cardiovascular comorbidity, \% & 40.6 & 37.2 & 38.9 \\
\hline PsA subtype: \% & & & \\
oligo & 25.6 & 28.5 & 27.0 \\
poly & 63.0 & 61.6 & 62.3 \\
axial (isolated or combined & 38.1 & 27.8 & 32.8 \\
with other subtyp) & & & \\
\hline Enthesitis present, \% & 47.6 & 47.9 & 47.8 \\
Leeds Enthesitis Index & $2.6(1.4)$ & $2.5(1.3)$ & $2.6(1.4)$ \\
\hline Dactylitis present, \% & 20.1 & 21.8 & 21.0 \\
\hline BSA, \% & & & \\
<3\% & 36.3 & 50.4 & 43.3 \\
3\%-10\% & 35.0 & 33.2 & 34.1 \\
\hline$>10 \%$ & 28.8 & 16.4 & 22.6 \\
\hline Nail disease, \% & 43.5 & 37.2 & 40.3 \\
\hline DAS28 & $4.3(1.2)$ & $4.1(1.3)$ & $4.2(1.3)$ \\
\hline DAPSA & $33.6(21.1)$ & $31.9(18.9)$ & $32.7(20.0)$ \\
\hline Swollen Joint Count (66) & $5.9(7.8)$ & $5.6(6.3)$ & $5.8(7.1)$ \\
\hline Tender Joint Count (68) & $12.8(12.7)$ & $11.4(10.2)$ & $12.1(11.5)$ \\
\hline CRP (mg/dl), median (IQR) & $0.7(0.3,1.6)$ & $0.7(0.3,1.6)$ & $0.7(0.3,1.6)$ \\
\hline
\end{tabular}

Conclusions: European PsA patients starting bDMARDs in 2016/2017 frequently presented with moderate to high disease activity, and overlapping subtypes of PsA, mainly polyarticular disease. Comorbidities, predominantly 